\title{
The effect of dietary phytochemicals on nuclear factor erythroid 2-related factor 2 (Nrf2) activation: a systematic review of human intervention trials
}

\author{
Tom Clifford ${ }^{2}$ (1) - Jarred P. Acton ${ }^{2} \cdot$ Stuart P. Cocksedge ${ }^{2} \cdot$ Kelly A. Bowden Davies $^{1} \cdot$ Stephen J. Bailey $^{2}$
}

Received: 29 October 2020 / Accepted: 28 November 2020 / Published online: 30 January 2021

(c) The Author(s) 2021

\begin{abstract}
We conducted a systematic review of human trials examining the effects of dietary phytochemicals on Nrf2 activation. In accordance with the PRISMA guidelines, Medline, Embase and CAB abstracts were searched for articles from inception until March 2020. Studies in adult humans that measured Nrf2 activation (gene or protein expression changes) following ingestion of a phytochemical, either alone or in combination were included. The study was pre-registered on the Prospero database (Registration Number: CRD42020176121). Twenty-nine full-texts were retrieved and reviewed for analysis; of these, eighteen were included in the systematic review. Most of the included participants were healthy, obese or type 2 diabetics. Study quality was assessed using the Cochrane Collaboration Risk of Bias Assessment tool. Twelve different compounds were examined in the included studies: curcumin, resveratrol and sulforaphane were the most common ( $n=3$ each). Approximately half of the studies reported increases in Nrf2 activation $(n=10)$; however, many were of poor quality and had an unclear or high risk of bias. There is currently limited evidence that phytochemicals activate Nrf2 in humans. Well controlled human intervention trials are needed to corroborate the findings from in vitro and animal studies.
\end{abstract}

Keywords Polyphenols $\cdot$ Antioxidants $\cdot$ Oxidative stress $\cdot$ Redox balance $\cdot$ Nutrition

\section{Introduction}

Phytochemicals, defined as plant metabolites, are ubiquitous in the human diet [1]. Indeed, several thousand different phytochemicals have been identified in commonly consumed plants [2]. These phytochemicals can be sub-divided into four higher order classes, based on their chemical structure: phenols and polyphenols, terpenoids, alkaloids, and sulphur containing compounds [2]. Although not deemed essential for health, numerous longitudinal studies report positive associations between the intake of phytochemicals and

Supplementary information The online version of this article (https://doi.org/10.1007/s11033-020-06041-x) contains supplementary material, which is available to authorized users.

Tom Clifford

t.clifford@lboro.ac.uk

1 Department of Sport and Exercise Sciences, Manchester Metropolitan University, Manchester M15 6BH, UK

2 School of Sport, Exercise and Health Sciences, Loughborough University, Loughborough LE11 3TU, UK health, including a lowered risk of cardiovascular, neurodegenerative, and metabolic disease [3-8]. For example, in a large study of more than 5000 Finnish adults, higher intakes of flavonoids, the major class of polyphenols in the human diet, was associated with a reduced risk of heart disease [8]. Similarly, intake of anthocyanins, polyphenols present in many fruits, was associated with a reduced risk of myocardial infarction in $\geq 90,000$ middle-older age women [7]. These findings have sparked significant interest in elucidating the wider health promoting potential of phytochemicals and resolving the molecular bases of such effects.

Several putative mechanisms for the potential health promoting effects of phytochemicals have been postulated, with their function as antioxidants receiving the most attention. Although many different definitions of antioxidants exist, they are recognized as agents that donate electrons to, and thereby stabilize, oxidants to prevent them from oxidizing other molecules $[9,10]$. While some degree of oxidation is an important and necessary biological process, an excessive increase in reactive species (also referred to as free radicals) that exceeds antioxidant capacity leads to oxidative stress and the associated oxidative damage to proteins, lipids, 
DNA and other molecules [10,11]. Hence, excess production of reactive species is implicated in the initiation and progression of several diseases $[12,13]$. To protect against oxidative damage, cells are endowed with an antioxidant defense system, which includes various antioxidant enzymes including superoxide dismutase, catalase, and glutathione peroxidase [14]. Under normal conditions, endogenous antioxidants maintain cellular redox state by effectively scavenging radicals $[9,10]$. However, exposure to a stressor that augments oxidant production (e.g., chronic disease, exercise, pollutants, injury) can overwhelm endogenous cellular antioxidant defenses [14]. In such circumstances, exogenous phytochemicals or dietary antioxidants like vitamin $\mathrm{C}$ and $\mathrm{E}$ (collectively referred to as non-enzymatic antioxidants) might be needed to maintain cellular redox status and offset protein, lipid, and DNA oxidation $[9,11]$.

The antioxidant effects of phytochemicals have been largely ascribed to radical scavenging [15, 16]. Indeed, phytochemicals, including curcumin, resveratrol, and quercetin have been shown to scavenge reactive species in vitro $[17,18]$. In human studies, direct measurement of reactive species is more challenging due to their high reactivity and short biological half-lives [19]. Instead, antioxidant effects are often inferred by measuring tissue concentrations of oxidation products, such as protein carbonyls or $\mathrm{F} 2$-isoprostanes $[19,20]$. Although findings are inconsistent [21], there is evidence that phytochemicals can lower systemic or cellular levels of lipid or protein oxidation in humans, suggestive of antioxidant effects [22-25].

Although the radical scavenging observed in vitro is often extrapolated and used to explain the antioxidant effects of phytochemicals in vivo, this contention has been questioned [26]. Perhaps the best evidence to undermine direct antioxidant effects of phytochemicals in vivo is the fact that most phytochemicals are extensively metabolized and have poor bioavailability, such that systemic concentrations typically reached after ingestion $(\sim 1 \mu \mathrm{mol} / \mathrm{L})$ are significantly lower than the concentrations required to directly scavenge reactive species [26-28]. Instead, the major mechanism for the antioxidant or biological effects of phytochemicals in vivo is increasingly being attributed to their induction of the redox sensitive transcription factor, nuclear erythroid 2-related factor 2 (Nrf2) [26, 29].

In response to homeostatic challenges Nrf2 upregulates $\sim 250$ cytoprotective genes, many of which code for proteins with antioxidant, anti-inflammatory or phase 2 detoxifying functions [30]. Nrf2 is primarily regulated by cysteine-rich kelch-like ECH associated protein 1 (Keap1), which sequesters Nrf2 in the cytosol through continual ubiquination [31,32]. By reacting with cysteine residues on Keap-1, reactive species or electrophiles remove its repressive functions and enable Nrf2 to accumulate [33, 34]. After dissociating from Keap-1, Nrf2 translocates to the nucleus where it forms a heterodimer with musculoaponeurotic fibrosarcoma proteins to activate the antioxidant response element (ARE)-DNA sequence (also referred to as the electrophile response element) [32, 35].

The various mechanisms by which phytochemicals activate $\mathrm{Nrf2}$ are still being unraveled; however, a few of these have been well-described in the literature. Indeed, two prominent mechanisms are that phytochemicals initiate the Nrf2ARE pathway by modifying cysteine residues on Keap-1, either by acting as electrophilic Michael acceptors, many after biotransformation to reactive quinones, or by upregulating protein kinases that phosphorylate $\mathrm{Nrf} 2$ and facilitate its dissociation from Keap-1 [36-38]. These actions suggest, somewhat paradoxically, that phytochemicals may confer antioxidant effects indirectly and as a result of their initial pro-oxidant effects $[26,39]$. Since the reactions needed to stimulate Nrf2 are possible at the low, sub-toxic concentrations typically reported for phytochemicals [26], this substantiates the notion that the antioxidant effects phytochemicals are more likely to be indirect. Specifically, activating Nrf2 will upregulate synthesis of several antioxidant enzymes [40-42]. Given that oxidative stress and low grade inflammation underlie the pathogenesis of many degenerative chronic diseases, Nrf2 has emerged as an attractive therapeutic target for health promotion and disease prevention $[30,43]$.

The Nrf2 inducing effects of various phytochemicals have been well-described in the literature with activation of the Nrf2-ARE axis now recognized as the major mechanism by which phytochemicals mitigate pro-oxidative and proinflammatory insults [27, 44]. However, most of the research reporting Nrf2 induction with phytochemicals has been conducted in pre-clinical cell culture or animal models. These studies typically use supra-physiological doses that are not achievable with normal dietary intakes. In the few studies that have assessed the effect of dietary phytochemicals on Nrf2 activation in humans, conflicting findings have been reported [45-47]. As such, there is currently no consensus on the effectiveness of phytochemicals to activate Nrf2 in humans. Thus, the aim of the present systematic review was to evaluate the extant literature and determine the impact of dietary phytochemicals on Nrf2 activation in humans. This systematic review was conducted according to the Preferred Reporting Items for Systematic Reviews and Meta-Analyses (PRISMA) guidelines [48]. Given the emerging beneficial health effects associated with Nrf2 activation, determining the effectiveness of dietary components on its activation is a critical step in understanding how the Nrf2-ARE pathway can be therapeutically harnessed. 


\section{Methods}

The protocol for this systematic review was pre-registered on the PROSPERO database (Registration Number: CRD42020176121) and reported according to the PRISMA guidelines [48].

\section{Search strategy}

Medline, Embase and CAB abstracts were searched for articles from inception until March 2020. Our search strategy was based on a Population, Intervention, Comparator, Outcome, Study design (PICOS) methodology (available in the Online Supplementary Material). Using Boolean logic and truncations, a comprehensive list of terms and keywords were searched that linked "phytochemical" and "Nrf2". Our terms and key words were adapted from similarly designed review articles $[49,50]$. Because over 60 terms were entered, these are not reproduced here but are available in the Online Supplementary Material. Search terms were applied to the full texts; non-English studies were included in our search.

The titles and abstracts of the articles were screened independently by two investigators (TC and KBD). The relevant full texts were retrieved to assess eligibility according to the criteria outlined below. All full-text articles included were searched manually for any additional studies; one was identified from this search [51]. Another [52], was identified from a Google Scholar search performed at this stage. A flow diagram of our search strategy is depicted in Fig. 1.

\section{Study selection}

Inclusion criteria were: (1) adult participants ( $\geq 18$ years); (2) administration of a dietary phytochemical (or a combination of phytochemical compounds); (3) reporting of pre to post changes in Nrf2 via any methods and in any tissue. No restrictions were added for study design, but we excluded studies in animals. The full text of articles deemed to meet these criteria were retrieved and independently screened for their eligibility by all investigators (see Online Supplementary Material for list of studies excluded). All investigators agreed on the articles to be included in the systematic review.

\section{Data extraction}

Data were extracted by three authors (TC, SC and SB). The data were based on our PICOS (see Online Supplementary Material) and included type of participants and their age, the study design, the interventions, duration of intake, type of measurement (e.g., protein, gene expression etc.), tissue type, and outcome. Because of the wide inter-study heterogeneities in study design and interventions, a meta-analysis was deemed inappropriate. Extracted data is displayed in Table 1.

\section{Risk of bias}

Study quality was assessed with the Cochrane Risk of Bias Tool [53] from Review Manager 5.3 (Cochrane Collaboration, UK). This was performed independently by two authors (TC and JA) and disagreements were resolved through discussion. Each study was rated as either low, unclear or high risk of bias according to the following criteria: random sequence generation, allocation concealment, blinding of participants and personnel, blinding of outcome assessment, incomplete outcome data, selective reporting, and "other" potential biases (e.g., conflicts of interest, inadequate study design).

\section{Results}

\section{Search results}

Results from our search strategy are presented in Fig. 1. We identified 2341 articles from three databases, which was reduced to 2123 after removing duplicates. After initial screening of abstracts and titles, we retrieved twenty-nine full texts; eleven were excluded and eighteen were deemed eligible and included in the review.

\section{Study characteristics}

Table 1 summarizes the studies examining the effects of phytochemicals on Nrf2. Across the 18 included studies, 12 different phytochemicals were examined for Nrf2 activation. Only three individual phytochemicals were measured in more than one study; these were curcumin [54-56], resveratrol $[45,57,58]$ and sulforaphane $[46,59,60]$. Other phytochemicals examined were soybean-isoflavones [62], lycopene [63], fish oil [63], and co-enzyme Q-10 [64]. The chemical structures of these phytochemicals are shown in Fig. 2. Some studies examined the effects of a whole food or fluid rich in phytochemicals; these included tart cherry juice [52], seed oils [65], bilberry [66], whole grape powder [47] and phytochemical enriched coffee [51, 61].

Three of the included studies were pretest-posttest quasi experimental designs with no placebo comparator $[54,55$, 66]; seven studies employed a randomized crossover design [45, 51, 58-60, 65, 67]; eight employed a randomized parallel groups design [46, 52, 56, 57, 62-64].

In the included studies there was a total of 727 participants; average age ranged from 18 to 67 years. Nine trials 


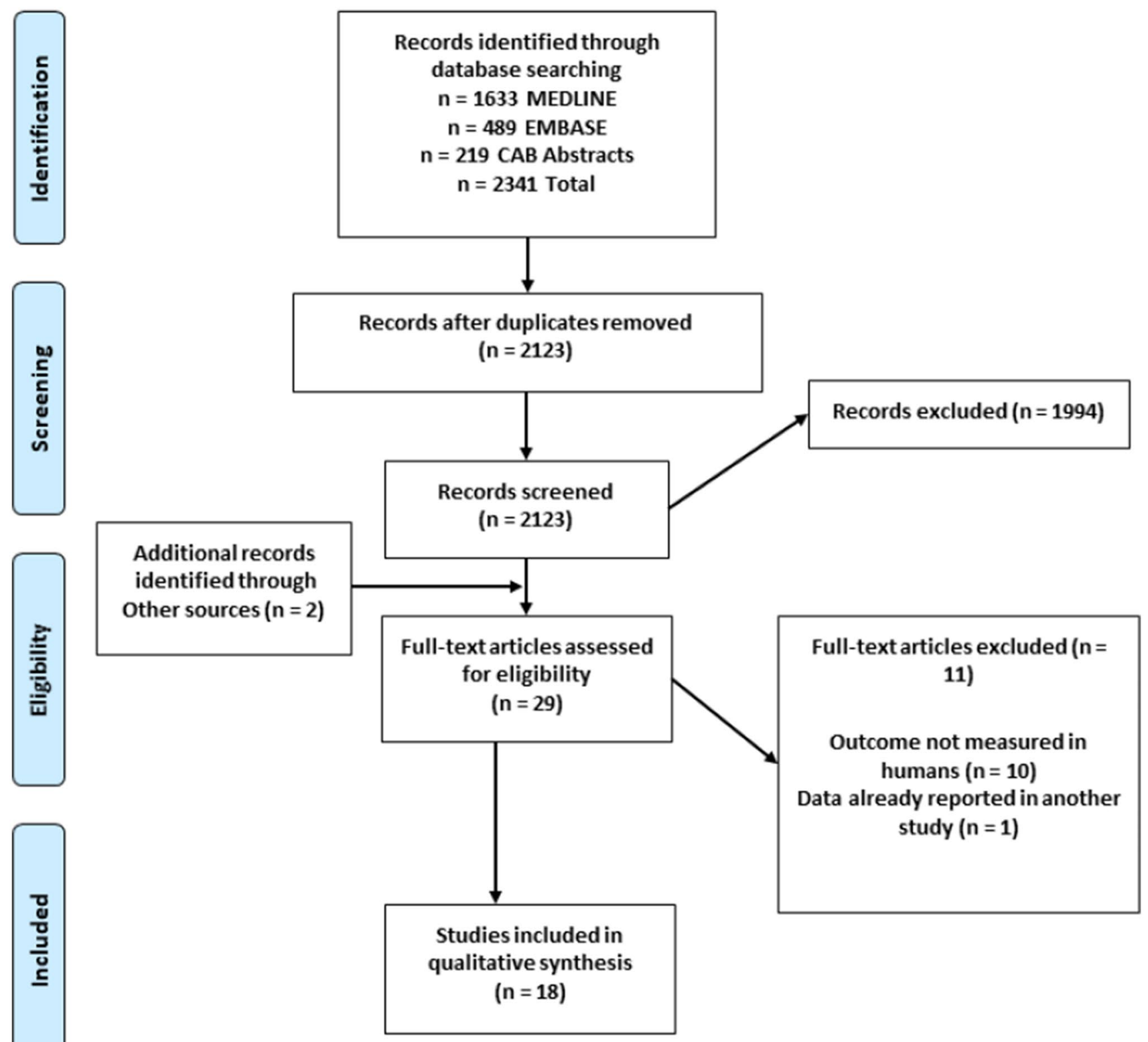

Fig. 1 Flow diagram of the process used in selection of the trials included in this systematic review

were performed in healthy, disease free adults $[45,51,52$, $55,59-61,64,66,68]$; three were in type 2 diabetics [54, $56,57]$; one was in chronic obstructive pulmonary disease patients [46]; two were in obese adults [65, 67]; one was in prostate cancer patients [63]; one was in ischemic stroke patients [62] and one was in chronic kidney disease patients [58]. Of these trials, only two were performed in adults $\geq 65$ years of age $[52,64]$. Of the seven trials in patients, only three recorded the intake of concomitant medications $[46,54,62]$.

The length of the dietary intervention ranged from a single dose $(n=4)$ to 24 weeks; however, only one was longer than 12 weeks [62]. The most common duration was four weeks $(n=6)$. There was wide heterogeneity in doses used, within and between supplements (Table 1).

Most studies $(n=14)$ measured Nrf2 activation in peripheral blood cells $[45,51,54,55,57,58,60,62$, 64-67, 69]. One measured Nrf2 in skeletal muscle [52]; one in prostate tissue [63]; one in skin [59]; one in nasal epithelial cells (as well as peripheral blood mononuclear cells; PBMCs) [60] and one in alveolar macrophages, bronchial epithelial cells and PBMCs [46].

Fifteen studies evaluated Nrf2 activation as gene expression [46, 47, 51, 52, 54, 55, 57-64, 66]; of these, three also measured protein levels $[62,64,65]$. One study 


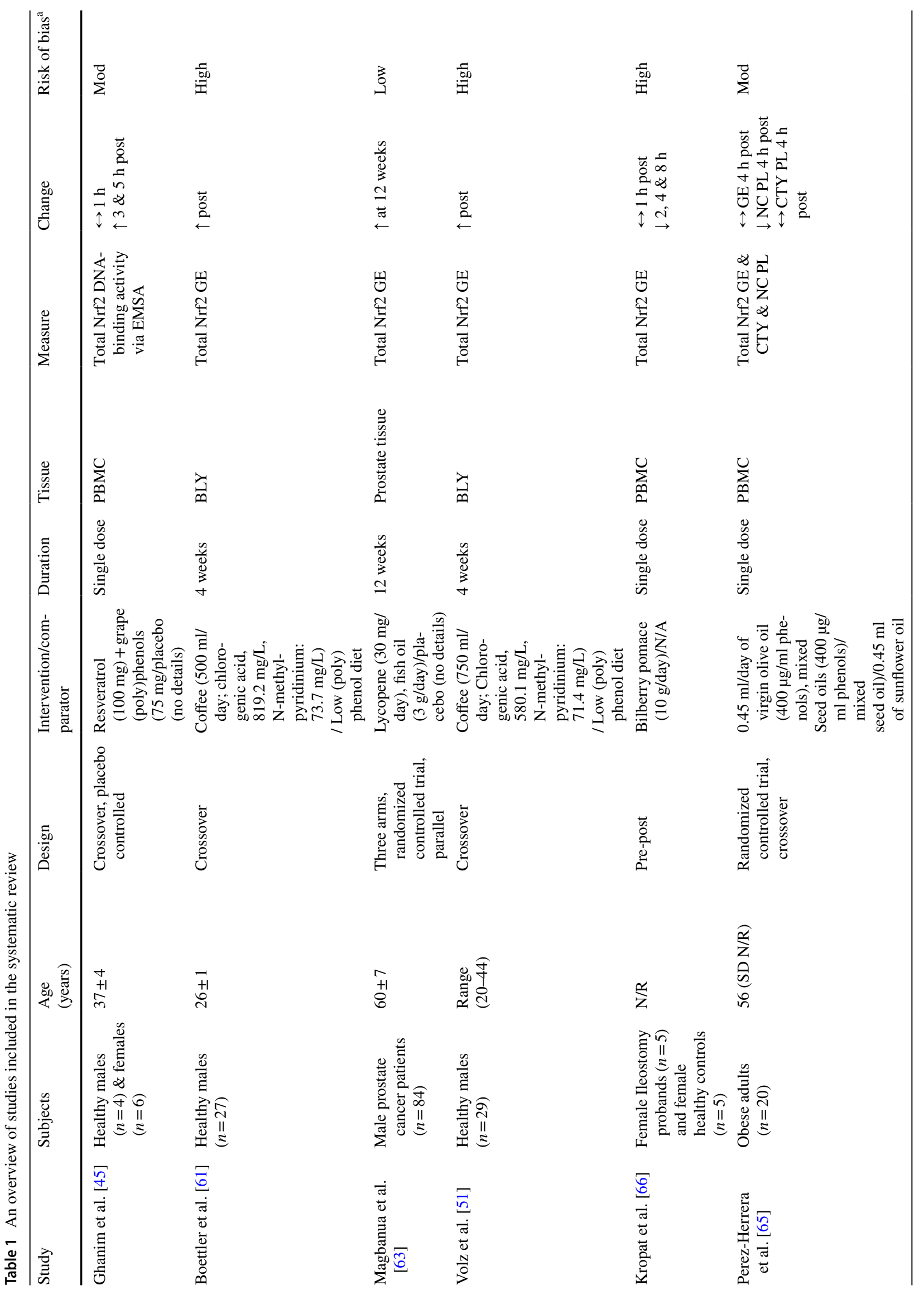




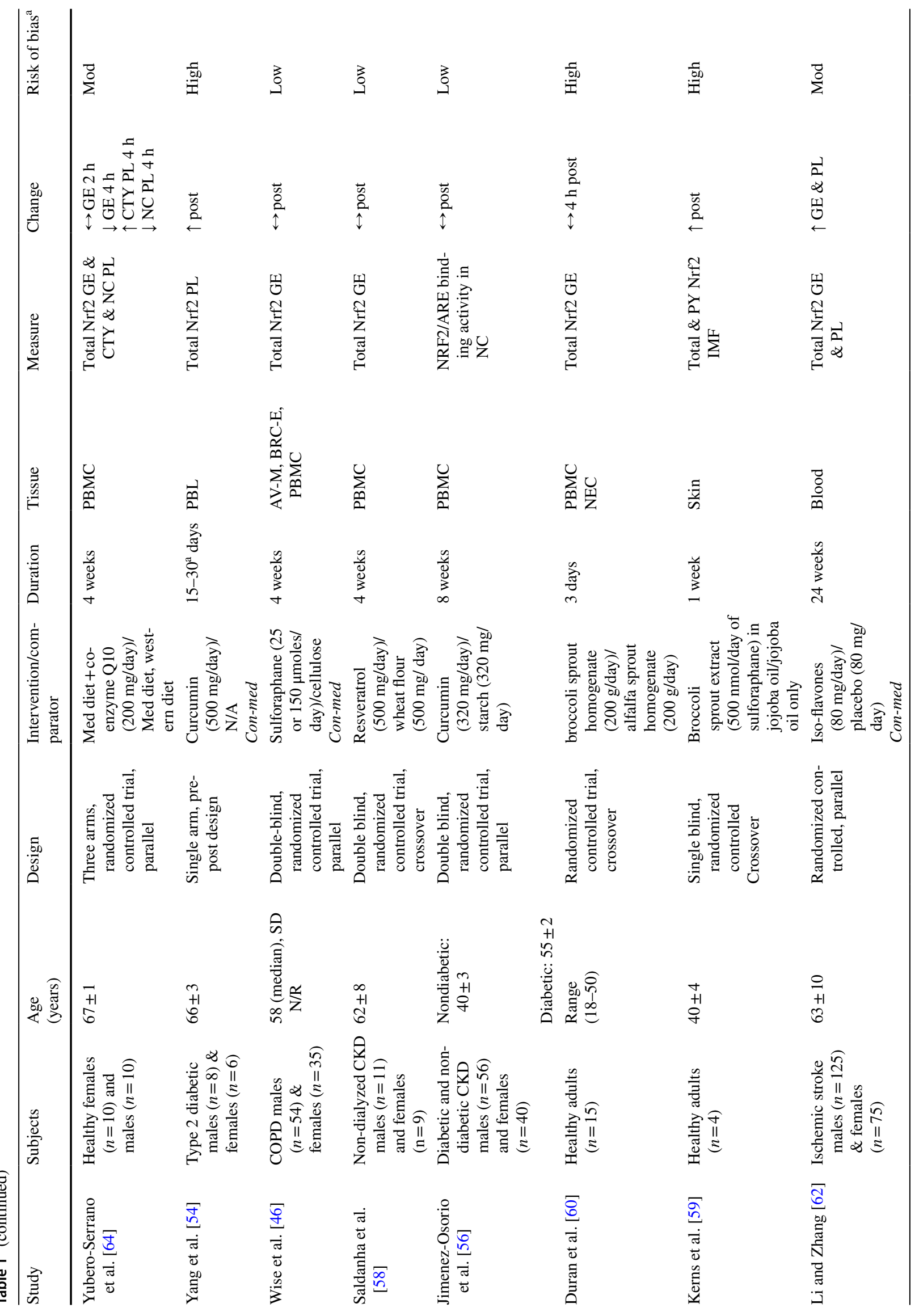




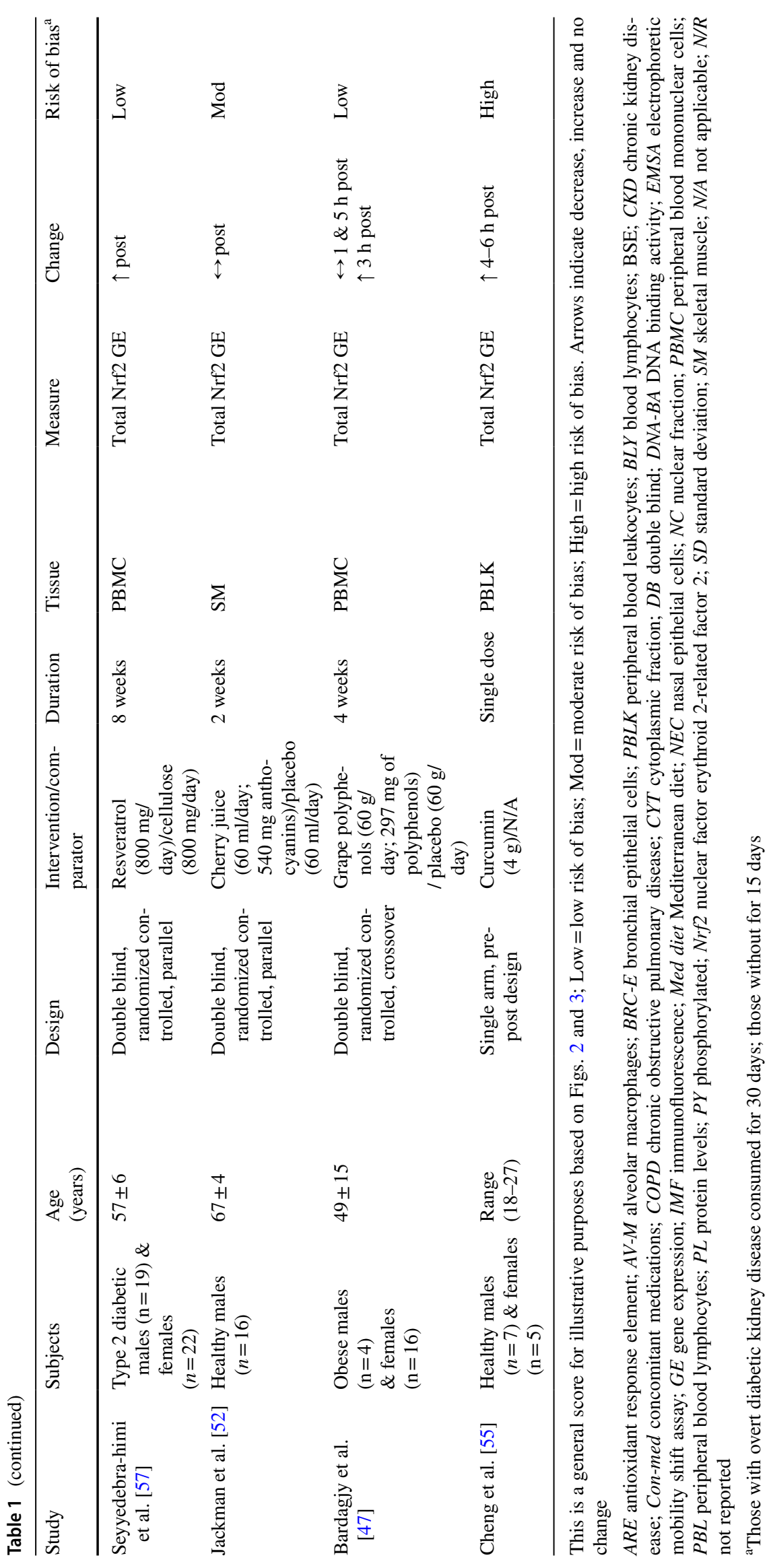


<smiles>COc1ccc(/C=C/c2cc(ON)cc(ON)c2)cc1</smiles>

Curcumin

Resveratrol<smiles>COc1ccc(-c2coc3cc(O)ccc3c2=O)cc1</smiles><smiles>O=c1c(-c2ccc(O)cc2)coc2cc(O)cc(O)c12</smiles><smiles>COc1ccc(-c2coc3cc(OC)c(OC)cc3c2=O)cc1</smiles>

Glycitein

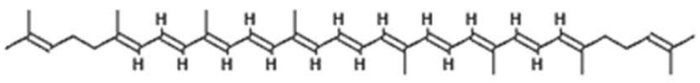

Lycopene

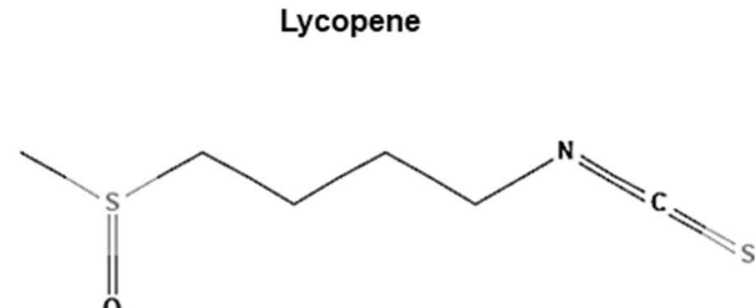

Sulforaphane

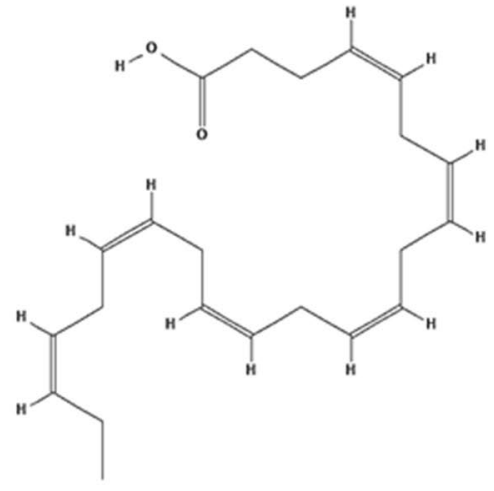

Docosahexaenoic acid

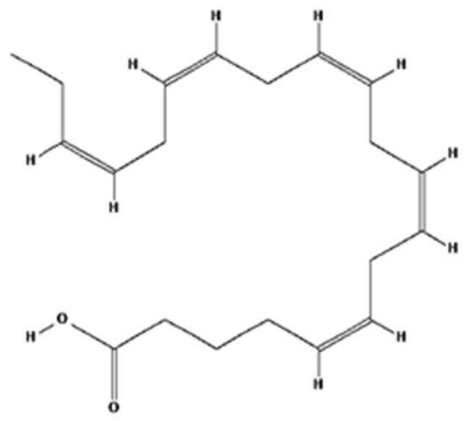

Eicosapentaenoic acid

Fish oil

Fig. 2 Chemical structures of main phytochemicals in the included studies. Structures from PubChem; references can be found in the Online Supplementary Material

measured protein levels only [54] and two studies measured Nrf2-DNA binding activity $[45,56]$.

\section{Phytochemicals examined in more than one trial}

\section{Coffee derived phytochemicals}

Boettler et al. [61] reported that a four-week intake of $500 \mathrm{ml} /$ day of coffee enriched with chlorogenic acid or n-methylpyridinium increased Nrf2 gene expression in 27 healthy young adults compared to a low polyphenol control diet. Similarly, Volz et al. [51] reported a significant 1.4 fold increase in Nrf2 gene expression in healthy individuals who consumed $750 \mathrm{ml}$ of a phytochemical rich coffee per day for four weeks versus a low polyphenol control diet.

\section{Curcumin}

Yang et al. [54] showed that $500 \mathrm{mg}$ of curcumin for 15 days significantly increased Nrf2 protein expression compared to baseline in type 2 diabetics. Similarly, in a pretest-posttest design in 12 healthy volunteers, Cheng et al. [55] found that $4 \mathrm{~g}$ of curcumin stimulated a 1.3 fold increase in Nrf2 gene expression 4-6 h post-intake. By contrast, another study [56] found no change to Nrf2-ARE binding activity in kidney disease patients who consumed $320 \mathrm{mg} /$ day of curcumin for eight weeks.

\section{Resveratrol}

A cocktail of resveratrol (100 mg) and grape polyphenols (75 mg) significantly increased Nrf2-ARE binding activity at $3 \mathrm{~h}(\sim 150 \%)$ and $5 \mathrm{~h}(\sim 100 \%)$ post consumption in 
10 healthy adults [45] In a randomized, crossover study, Saldanha et al. [58] found no change in Nrf2 gene expression $(-0.27$ fold $)$ with a four week intake of resveratrol $(500 \mathrm{mg} /$ day) in kidney disease patients. Another study reported a significant increase in $\mathrm{Nrf} 2$ gene expression in diabetic patients consuming $800 \mathrm{mg} /$ day of resveratrol for 2 months [57]. However, the reported values indicate that Nrf2 decreased with resveratrol supplementation (pre-intervention; $6.32 \pm 1.05$ vs. post-intervention $5.62 \pm 1.35$ ) (see "Discussion" below section).

\section{Sulforaphane}

Duran et al. [60] found no significant effect of a sulforaphane-rich broccoli sprout homogenate $(200 \mathrm{~g} /$ day for three days) on Nrf2 gene expression ( 0.9 to $-12.6 \%$ change) in fifteen healthy young adults. Similarly, Wise et al. [46] found that four weeks of sulforaphane (25-150 $\mu$ moles/day) did not significantly modify Nrf2 gene expression (max average fold change 1.17) in chronic obstructive pulmonary disease patients. In contrast, Kerns et al. [59] reported an increase in total and phosphorylated Nrf2 expression from four healthy subjects who applied broccoli sprout extract ( $500 \mathrm{nmol} / \mathrm{ml}$ of sulforaphane) to their arm for seven days.

\section{Phytochemicals measured in single trials}

Kropat et al. [66] found that an anthocyanin-rich bilberry extract ( $10 \mathrm{~g})$ significantly decreased Nrf2 gene expression 2,4 and $8 \mathrm{~h}$ post consumption ( -40 to $-60 \%$ of baseline) in female ileostomy probands and female healthy controls. Perez-Herrera et al. [65] examined whether adding $400 \mu \mathrm{g} /$ $\mathrm{ml}$ of phenolics to various seed oils would modify Nrf2 activation after a meal. They found no significant differences in Nrf2 gene expression 2 and 4 h post-intake but a $\sim 18$ to $25 \%$ decrease in Nrf2 content (nuclear fraction) $4 \mathrm{~h}$ post intake in the phenolic containing oils, compared to sunflower oil. Magbanua et al. [63] examined the effects of the carotenoid, lycopene ( $30 \mathrm{mg} /$ day), and fish oil ( $3 \mathrm{~g} /$ day) on Nrf2 gene expression in prostate tissue from prostate cancer patients. After 12 weeks, they found a significant increase in Nrf2 activation after both supplements compared to a placebo control. Yubero-Serrano et al. [64] reported a significant increase in cytosolic Nrf2 content (4 h post-food intake) in healthy individuals who consumed co-enzyme Q-10 (200 mg/day) alongside a Mediterranean diet for four weeks. In the same study, this intervention was also found to significantly reduce nuclear Nrf2 protein content and gene expression $4 \mathrm{~h}$ after a mixed macronutrient meal. A large randomized controlled trial [62] reported a significant increase in Nrf2 gene expression ( 40\%) and protein content $(\sim 30 \%)$ after a 24 week intake of isoflavones $(80 \mathrm{mg} /$ day $)$ in ischemic stroke patients. Jackman et al. [52] found that a 2-week intake of anthocyanin rich cherry juice $(60 \mathrm{ml} /$ day) had no effect on Nrf2 gene expression in skeletal muscle from 16 healthy older adults. By contrast, four-week intake of an anthocyanin rich mixture of grape polyphenols increased $\mathrm{Nrf} 2$ gene expression ( 1.2 fold) $3 \mathrm{~h}$ following a high fat, high carbohydrate meal [67].

\section{Risk of bias}

There was a large variation in study quality (Figs. 3 and 4). Only two $[46,58]$ of the eighteen trials were deemed to be sufficiently well conducted and reported to have a low risk of bias for all variables; neither of which reported an increase in Nrf2 activation after the intervention. Four studies had an unclear risk of bias for random sequence generation because of insufficient details were given or no randomization appeared to be performed $[45,54,55,66]$. Two studies were deemed to have a high risk of bias for sequence allocation because they did not randomize the treatment order; all participants had the control first and then the intervention after a washout period $[51,61]$. All but three studies [46, 57, 58] had an unclear or high risk of bias for allocation concealment because insufficient information was given. One study was deemed high risk for this variable because participants were told to avoid the intervention in the weeks leading up to the trial [55]. Nine studies had an unclear risk of bias for blinding of participants or personnel and blinding of outcome because insufficient details were provided [45, 51, 54, $55,60-62,65,66]$. One study had a high risk of bias because the assessors were not blinded to the intervention groups [59]. In four studies, it was unclear if there was attrition bias $[51,57,61,66]$. One study was considered high risk because the number of participants enrolled did not match the number reported for the outcomes and no explanation was provided for this discrepancy [60]. Five studies were judged to have an unclear risk of bias for selective reporting due to insufficient information [51, 55, 59, 61, 66]; two studies were deemed to have an unclear risk for other bias due to funding sources $[45,52]$ and two for a poorly described study design [51,61]. Three studies were deemed to have a high risk for other bias because the studies had no comparator control $[54,55,66]$.

\section{Discussion}

This is the first study to systematically review trials examining the effects of phytochemicals on Nrf2 activation in humans. Across 18 studies, 12 different phytochemicals were examined, of which curcumin, resveratrol and sulforaphane were the most frequent. More than half the studies found evidence of a Nrf2 inducing effect $(n=10)$; however, many of them had a high risk of bias and were poorly controlled. 


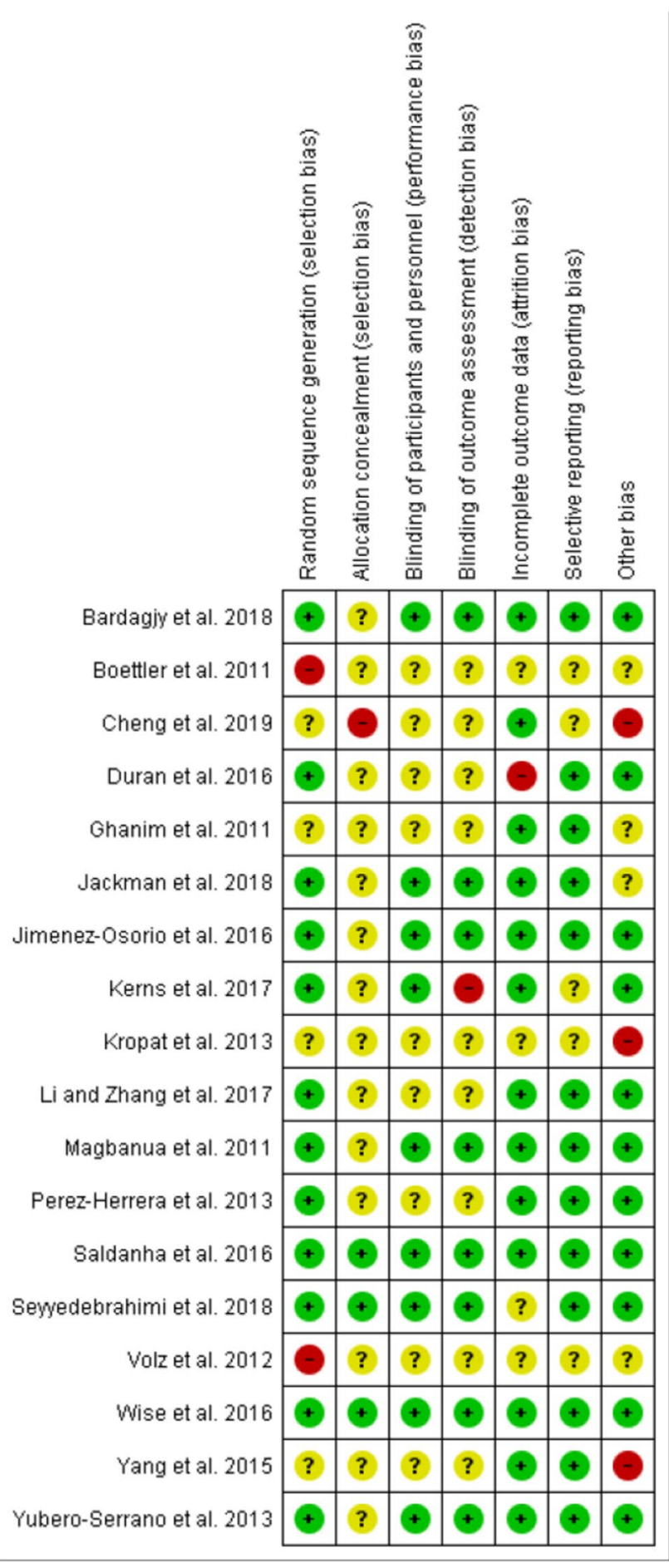

Fig. 3 Risk of bias summary for incldued studies

Overall, this study found limited high-quality evidence of phytochemicals activating Nrf2 in humans.

There was wide heterogeneity in study quality in human trials assessing the influence of phytochemical administration on Nrf2 activation. Many studies had an unclear or high risk of bias as a result of inadequate randomization, allocation concealment and blinding procedures. Three trials had an unclear or high risk of bias for most variables as they did not include a comparator control arm and instead employed pretest posttest quasi experimental designs [54, 55, 66]. In all three studies, Nrf2 activation was measured as changes in gene expression before and after the intervention only. These changes also might not translate to increases in Nrf2 protein content. Another limitation in many studies was low sample size. Eight studies contained less than twenty participants, and only two conducted a power analysis for measuring Nrf2 [46, 58]. Many did not state a primary outcome and of those that did only two reported that it was Nrf2 [46, 58]. Thus, it would be reasonable to assume that many of the studies were not adequately powered to detect effects, and that the risk of type two errors was high. Another potential source of bias was the lack of dietary control in the studies. Habitual dietary intake is an important confounding factor when evaluating the nutrigenomic effects of phytochemicals [70]; however, it was largely ignored by the included studies. Many trials did not state whether participants continued with their normal diet or altered their intakes during the study duration, and only three studies provided a detailed analysis of participants dietary intake [52, $64,67]$. Finally, and as evident from Table 1, the reporting of methods was poor in some studies, with many providing inadequate information for replication. In summary, more appropriately powered studies are needed to evaluate the efficacy of dietary supplementation with phytochemicals to enhance Nrf2 activation with Nrf2 as the primary outcome and, where possible, such studies should be conducted according to the Consolidated Standards of Reporting Trials (CONSORT) guidelines [71] so the highest quality evidence is obtained and reported.

In numerous in vitro studies, curcumin $[72,73]$ and resveratrol [74-76] have been shown to induce Nrf2 activation. Therefore, it is perhaps unsurprising that these were found to be the most studied polyphenols in humans. Curcumin has a Michael acceptor in the form of a $\alpha, \beta$-unsaturated carbonyl group and thus the main mechanism by which it activates Nrf2 is by alkylating a protein thiol on the Keap-1-Nrf2 binding complex, which allows Nrf2 to translocate to the nucleus to initiate antioxidant gene expression changes [34, 38, 73, 77]. Resveratrol does not contain a Michael acceptor but instead likely acquires electrophilic and therefore Nrf2 inducing capacity through oxidation to a reactive quinone [38].

In the three studies that administered curcumin, two were shown to increase Nrf2 activation and one had no effect. However, as mentioned above, neither of the studies reporting positive effects were randomized, placebo-controlled trials and therefore had a high risk of bias [54, 55]. For example, in one of these studies [55], Nrf2 expression was measured in twelve healthy volunteers before and after $4 \mathrm{~g}$ 
Random sequence generation (selection bias)

Allocation concealment (selection bias)

Blinding of participants and personnel (performance bias)

Blinding of outcome assessment (detection bias)

Incomplete outcome data (attrition bias)

Selective reporting (reporting bias)
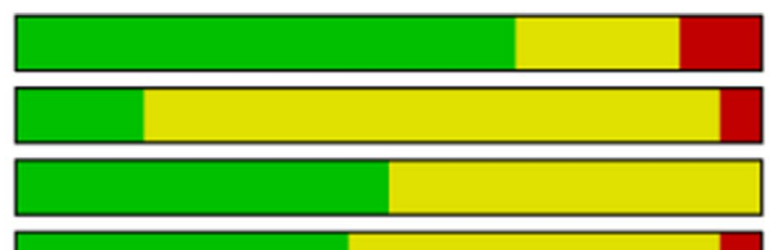

Other bias
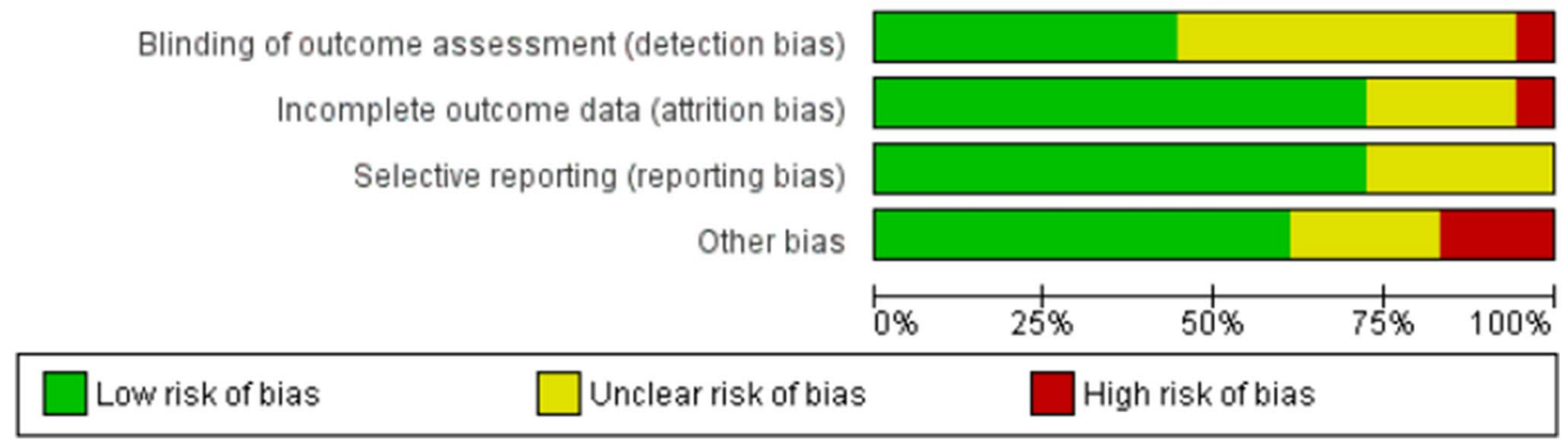

Fig. 4 Risk of bias summary for individual studies

of curcumin and a mixed macronutrient breakfast. While 4-6 $\mathrm{h}$ post Nrf2 gene expression was $\sim 1.3$ fold higher compared to baseline, there was no comparator group in this study and therefore it is not clear if this increase is a direct result of the curcumin. In contrast, the study by Jimenez and colleagues [56], was higher quality, employing a double blind, randomized, controlled design in a large cohort of diabetic patients. They found that eight weeks of curcumin (320 mg/day) had no effect on Nrf2 nuclear binding activity in PBMCs, despite curcumin lowering malondialdehyde, a marker of lipid peroxidation. This latter finding suggests that Nrf2 activation was not responsible for the lowering of oxidative stress and there must be other mechanisms by which curcumin functions as an antioxidant, perhaps by inhibiting oxidant producing immune cells $[78,79]$. Nevertheless, a decrease in only one marker (malondialdehyde) is not deemed sufficient to verify oxidative stress [80]; therefore, these results should not be interpreted as evidence of a strong antioxidant effect [20,81]. In summary, only one randomized controlled trial has examined the influence of curcumin administration on Nrf2 activation in humans and the results suggest that it was ineffective. Thus, there is currently no high-quality evidence showing that curcumin administration actives Nrf2 in humans.

Three studies examined the effects of resveratrol on Nrf2 activation. Two of these reported that resveratrol increased Nrf2 activation, either via DNA binding activity after a single dose [45] or via gene expression after two months of intake [57]. It should be noted that, in the former study, resveratrol was administered alongside $75 \mathrm{mg}$ of undisclosed grape polyphenols and thus these effects cannot necessarily be ascribed to resveratrol. Confusingly, the findings in the latter study [57] do not match how the data was interpreted; the authors state that resveratrol increased Nrf2 expression and discuss these findings accordingly, yet the data they present shows that resveratrol decreased Nrf2. The authors were contacted to clarify these findings, but no response was received. In contrast to these studies, a study with 20 chronic kidney disease patients found that four weeks of resveratrol $(500 \mathrm{mg} /$ day) had no effect on $\mathrm{Nrf} 2$ gene expression in PBMCs [58]. To explain their null findings, the authors speculated that the dose was too low, citing that the bioavailability of resveratrol was probably compromised in patients with renal impairments. However, they did not measure tissue levels of resveratrol or its metabolites to confirm this supposition. Overall, there is weak evidence that resveratrol increases Nrf2 activation in humans and therefore more high-quality research is required to corroborate or refute the in vitro and animal data.

In three studies the principal compound administered was sulforaphane, an isothiocyanate phytochemical present in cruciferous vegetables such as broccoli [82]. From a mechanistic perspective, sulforaphane is an electrophile that can synthesize Nrf2 by reacting with the sulphur-rich cysteine residues on its repressor Keap-1 [83, 84]. Sulforaphane is perhaps the most well studied Nrf2-activating compound to date, partly owing to its superior bioavailability to other phytochemicals $[82,85]$. There are now several clinical trials showing that sulforaphane attenuates inflammation and upregulates Nrf2 target genes in a range of pathologies [86-88]. Intriguingly, these effects are largely ascribed to Nrf2 activation, yet we found little evidence that sulforaphane activates Nrf2 in humans. In the one study reporting positive effects [59], the findings were biased by a low sample size (4 subjects) and inadequate blinding of assessors. In addition, the authors did not state whether the 
increase in Nrf2 expression was statistically significant. In contrast, a broccoli sprout homogenate that contained an undisclosed amount of sulforaphane, and possibly other bioactive compounds, had no effect on gene expression in PBMCs or nasal epithelial cells (Duran et al. 2016). This study was also hampered by a small sample size $(n=15)$. Nonetheless, their findings are consistent with a well-controlled clinical trial that found no effects of sulforaphane on Nrf2 activation in chronic obstructive pulmonary disease patients [46]. In this study, the authors speculated that persistent redox and immune dysregulation in this population could have rendered the intervention less effective. This postulate is inconsistent with studies that found sulforaphane upregulated Nrf2 target genes in type 2 diabetics [88] and obese patients [87], who also have high levels of oxidative stress and low grade inflammation. However, as these studies did not measure Nrf2, it is possible that the cytoprotective effects reported with sulforaphane were independent of the Nrf2-ARE pathway. There is evidence that sulforaphane inhibits inflammation by blunting the pro-inflammatory transcription factor nuclear factor kappa B (NF- $\mathrm{kB}$ ), which provides some support for Nrf2-ARE independent effects of sulforaphane administration [89]. In summary, we found little evidence that sulforaphane activates Nrf2 in humans. Since there are several ongoing clinical trials with sulforaphane containing supplements, evidence to support the efficacy of sulforaphane as a Nrf2 activator in humans will hopefully become clearer over the next few years.

Two studies reported that daily intake of $500-750 \mathrm{ml}$ of coffee made from beans enriched with chlorogenic acid or n-methylpyridinium increased Nrf2 gene expression in healthy young adults $[51,61]$. Despite these positive findings, it is important to note that both studies had a high risk of bias on the bases that no randomization was performed, there was no mention of double blinding, and the comparator arm was a low polyphenol diet with no information provided on what constituted a low polyphenol diet. Thus, while these studies are promising, well-controlled randomized trials are needed to confirm the efficacy of coffee consumption to increase Nrf2 activation.

The duration of supplementation varied widely across all studies, and there did not seem to be any specific pattern to discern the optimal length of the intervention. Indeed, Nrf2 activation increased with a single dose [45] or after several weeks of intake in others $[62,63]$. There is presently no consensus as to what the optimal dose or duration is for activating Nrf2 with phytochemicals or drugs [30, 82]. The optimal dose will not only depend on the quantity administered, but on its bioavailability, concentration reached in target cells, and the patients' age and health status [30]. Well-controlled, multiple dose, pharmaco-kinetic studies in a variety of patient groups and tissues will be needed to acquire this knowledge.
It has been shown that Nrf2 activation declines with age $[90,91]$ and is downregulated in diseases such as type 2 diabetes [92] and atherosclerosis [93]. In view of this, it could be speculated that older, diseased individuals are more likely to benefit from an intervention attempting to reestablish Nrf2 activation than young, healthy individuals, in whom Nrf2 activation is unlikely to be impaired. However, this might not be the case for patients on some medications. Indeed, it would be reasonable to assume that some medications which modulate redox signaling might interfere with $\mathrm{Nrf} 2$ activation, in which case it would be difficult to determine the independent effect of a phytochemical intervention on this pathway in some patient populations. Notwithstanding these potential confounders, this review found no clear evidence that age, health or medications modified the efficacy of the phytochemical interventions on Nrf2 activation. Indeed, as shown in Table 1, findings in young and healthy, or diseased individuals, were equally mixed, such that no discernable pattern emerged to suggest better or worse efficacy in a specific population or in those on concomitant medications. While Nrf2 was activated with isoflavones in stroke patients (almost half of whom were on medication) [62] and fish oil and lycopene in prostate cancer patients [63], in what were large relatively well controlled trials, it would be premature to suggest these populations could benefit from these interventions based on findings from isolated studies. Equally, the null effects of curcumin in diabetic patients [56] or sulforaphane in chronic obstructive pulmonary disease patients [46] should be not seen as definitive evidence that they are ineffective in these diseases. Ultimately, there were too few studies in any one population to discern what diseases or conditions these phytochemicals can or cannot modify Nrf2 activation.

Interestingly, in three studies there was evidence that phytochemicals decreased Nrf2 activation [64-66]. These studies differed markedly in terms of study design, participants and compounds used (bilberry pomace, co-enzyme Q10, phenolic-rich seed oils) and thus an explanation for their effects is unclear. Many phytochemicals have antiinflammatory effects [94] and therefore one possible explanation is that these compounds attenuated immune cell derived reactive species that activate Nrf2. However, this was not explored in either study. It is also possible that these phytochemicals promoted Nrf2 degradation; somewhat paradoxically, there is in vitro evidence that certain flavonoids can inhibit Nrf2 activation [95]. However, these observations remain contentious and the mechanisms have not been elucidated [96]. The ability of different phytochemicals to attenuate $\mathrm{Nrf} 2$ activation clearly requires further research. 


\section{Recommendations for future research}

Based on the findings of this review, a number of recommendations for future studies can be provided. Ideally, future trials will be randomized, placebo controlled and have a low risk of bias, like some in this review [46, 58, 63]. Although most phytochemicals are generally recognized as safe, it is important that trials record any adverse effects so that dosing regimens can be modified if necessary. These studies are required before titration studies to determine optimal doses and durations are considered. Trials are needed in both healthy and diseased populations of different ages, and confounding factors such as dietary intake, medication, ethnicity, body mass, and physical activity levels should be accounted for in randomization and analysis. Stage of disease progression is also another important factor to consider. This is highlighted by the ongoing work in cancer, which suggests that Nrf2 can have both a positive and detrimental role in cancer survival depending on the stage of the disease [96, 97]. In terms of measurement, Nrf2 activation can be evaluated in PBMCs and other accessible tissues (nasal cells etc.) with relative ease through gene expression and/or protein content assays. An obvious caveat is that these cells might not reflect changes in the target tissue. However, at least in PBMCs, changes in immune and redox signaling have been shown to strongly correlate with changes in several organs [98, 99]. Furthermore, Nrf2 is highly expressed in blood cells and therefore easily detectable [30]. A discussion of the methods used to quantify Nrf2 in these matrices is beyond the scope of this review but measuring total and phosphorylated Nrf2 in nuclear and cytosolic fractions at the gene and protein level would provide the most comprehensive data. It might also be useful to evaluate $\mathrm{Nrf} 2$ effects at multiple time-points to avoid missing any transient changes. In the present review, single dose studies showed that changes in gene and protein expression were not evident until 3-5 h post-intake and thus the timing of Nrf2 measurement might be an important consideration for future research. It would also be useful to measure Nrf2 activation alongside downstream genes such as superoxide dismutase, catalase, glutathione peroxidase, glutathione $s$-transferase, heme oxygenase 1 , glutathione and thioredoxin, which participate in cellular defense and have longer half-lives than Nrf2 [30]. Various phytochemicals have been shown to upregulate these and other Nrf2 target genes in humans [86-88, 100, 101]; however, as highlighted by this review, few studies also include measures of Nrf2, meaning these effects cannot be causally linked to activation of the Nrf2-ARE pathway. Many of the target genes such as heme oxygenase
1 and catalase can be upregulated by Nrf2-independent pathways [102-105], which could explain, at least in part, why some of the included studies report a disparity in the activation of Nrf2 and Nrf2 target genes [51, 57, 64-66]. In addition, systemic concentrations of the phytochemicals administered and where relevant its metabolites should be measured using appropriate techniques (e.g., liquid chromatography-mass spectroscopy). The bioavailability of the dietary phytochemicals was overlooked by almost all studies in this review and should be prioritized in future trials. Finally, future studies should explore the potential synergistic, additive or antagonistic effects of different phytochemical combinations on Nrf2 activation. There is growing evidence that the biological activity of some phytochemicals, such as curcumin, is augmented by the addition of piperine, partly as a result of improved bioavailability $[106,107]$. Combinations such as these are worth exploring in future studies. Collectively, the outlined measures will help to ensure the data collected is high quality and able to advance our current understanding of how dietary phytochemical interventions modulate Nrf2 activation in humans.

\section{Conclusions}

The current review provides a systematic summary of the evidence for administration of dietary phytochemicals to induce Nrf2 in humans. According to our review, there is insufficient high-quality evidence indicating that phytochemicals activate Nrf2 in humans. While many phytochemicals increased Nrf2 activation in single studies, it would be premature to single out any one specific compound due to the overall paucity of well controlled clinical trials and the diverse findings reported. Of critical importance moving forward is that future studies examine if the positive findings reported in cell culture and animal studies are translatable to humans. The pleiotropic role of Nrf2 in modulating system wide cytoprotective defenses means targeting this single transcription factor has the potential to improve health outcomes in a myriad of pathologies. While phytochemicals are unlikely to be as potent as the pharmacological agents currently being developed to activate Nrf2, they could play an important role as cost-effective, complementary, or preventative therapies. We hope these findings provide researchers with the impetus to conduct high quality human intervention studies examining the effects of dietary phytochemicals on Nrf2 activation.

Funding The authors received no funding or sponsorship for this work. 


\section{Compliance with ethical standards}

Conflict of interest All authors declare that they have no conflict of interest.

Open Access This article is licensed under a Creative Commons Attribution 4.0 International License, which permits use, sharing, adaptation, distribution and reproduction in any medium or format, as long as you give appropriate credit to the original author(s) and the source, provide a link to the Creative Commons licence, and indicate if changes were made. The images or other third party material in this article are included in the article's Creative Commons licence, unless indicated otherwise in a credit line to the material. If material is not included in the article's Creative Commons licence and your intended use is not permitted by statutory regulation or exceeds the permitted use, you will need to obtain permission directly from the copyright holder. To view a copy of this licence, visit http://creativecommons.org/licenses/by/4.0/.

\section{References}

1. Frank J, Fukagawa NK, Bilia AR et al (2019) Terms and nomenclature used for plant-derived components in nutrition and related research: efforts toward harmonization. Nutr Rev. https://doi. org/10.1093/nutrit/nuz081

2. Crozier A, Yokota T, Jaganath IB, Marks S, Saltmarsh M, Clifford MN (2007) Secondary metabolites in fruits, vegetables, beverages and other plant-based dietary components. In: Crozier A, Clifford MN, Ashihara H (eds) Plant secondary metabolites: occurrence, structure and role in the human diet. Blackwell Publishing, Oxford. https://doi.org/10.1002/9780470988558.ch7

3. Cassidy A, Bertoia M, Chiuve S, Flint A, Forman J, Rimm EB (2016) Habitual intake of anthocyanins and flavanones and risk of cardiovascular disease in men. Am J Clin Nutr. https://doi. org/10.3945/ajen.116.133132

4. Hertog MGL, Feskens EJM, Kromhout D et al (1993) Dietary antioxidant flavonoids and risk of coronary heart disease: the Zutphen Elderly Study. Lancet. https://doi.org/10.1016/01406736(93)92876-U

5. Guasch-Ferré M, Hu FB, Martínez-González MA et al (2014) Olive oil intake and risk of cardiovascular disease and mortality in the PREDIMED Study. BMC Med. https://doi. org/10.1186/1741-7015-12-78

6. Fraga CG, Croft KD, Kennedy DO, Tomás-Barberán FA (2019) The effects of polyphenols and other bioactives on human health. Food Funct. https://doi.org/10.1039/c8fo01997e

7. Cassidy A, Mukamal KJ, Liu L, Franz M, Eliassen AH, Rimm EB (2013) High anthocyanin intake is associated with a reduced risk of myocardial infarction in young and middleaged women. Circulation. https://doi.org/10.1161/CIRCULATIO NAHA.112.122408

8. Knekt P, Järvinen R, Reunanen A, Maatela J (1996) Flavonoid intake and coronary mortality in Finland: a cohort study. Br Med J. https://doi.org/10.1136/bmj.312.7029.478

9. Pandey KB, Rizvi SI (2009) Plant polyphenols as dietary antioxidants in human health and disease. Oxid Med Cell Longev. https://doi.org/10.4161/oxim.2.5.9498

10. Sies H, Berndt C, Jones DP (2017) Oxidative stress. Annu Rev Biochem 86:715-748. https://doi.org/10.1146/annurev-bioch em-061516-045037

11. Valko M, Leibfritz D, Moncol J, Cronin MTD, Mazur M, Telser J (2007) Free radicals and antioxidants in normal physiological functions and human disease. Int J Biochem Cell Biol. https:// doi.org/10.1016/j.biocel.2006.07.001
12. Vitale G, Salvioli S, Franceschi C (2013) Oxidative stress and the ageing endocrine system. Nat Rev Endocrinol. https://doi. org/10.1038/nrendo.2013.29

13. Radak Z, Chung HY, Koltai E, Taylor AW, Goto S (2008) Exercise, oxidative stress and hormesis. Ageing Res Rev. https:// doi.org/10.1016/j.arr.2007.04.004

14. Birben E, Sahiner UM, Sackesen C, Erzurum S, Kalayci O (2012) Oxidative stress and antioxidant defense. World Allergy Organ J. https://doi.org/10.1097/WOX.0b013e3182439613

15. He J, Giusti MM (2010) Anthocyanins: natural colorants with health-promoting properties. Annu Rev Food Sci Technol. https://doi.org/10.1146/annurev.food.080708.100754

16. Skrovankova S, Sumczynski D, Mlcek J, Jurikova T, Sochor J (2015) Bioactive compounds and antioxidant activity in different types of berries. Int J Mol Sci. https://doi.org/10.3390/ ijms 161024673

17. Ak T, Gülçin I (2008) Antioxidant and radical scavenging properties of curcumin. Chem Biol Interact. https://doi. org/10.1016/j.cbi.2008.05.003

18. Mikstacka R, Rimando AM, Ignatowicz E (2010) Antioxidant effect of trans-Resveratrol, pterostilbene, quercetin and their combinations in human erythrocytes In vitro. Plant Foods Hum Nutr. https://doi.org/10.1007/s11130-010-0154-8

19. Marrocco I, Altieri F, Peluso I (2017) Measurement and clinical significance of biomarkers of oxidative stress in humans. Oxid Med Cell Longev. https://doi.org/10.1155/2017/6501046

20. Powers SK, Smuder AJ, Kavazis AN, Hudson MB (2010) Experimental guidelines for studies designed to investigate the impact of antioxidant supplementation on exercise performance. Int J Sport Nutr Exerc Metab. https://doi.org/10.1123/ ijsnem.20.1.2

21. Suen J, Thomas J, Kranz A, Vun S, Miller M (2016) Effect of flavonoids on oxidative stress and inflammation in adults at risk of cardiovascular disease: a systematic review. Healthcare. https ://doi.org/10.3390/healthcare4030069

22. Hussain T, Tan B, Yin Y, Blachier F, Tossou MCB, Rahu N (2016) Oxidative stress and inflammation: what polyphenols can do for us? Oxid Med Cell Longev. https://doi. org $/ 10.1155 / 2016 / 7432797$

23. Amiot MJ, Riva C, Vinet A (2016) Effects of dietary polyphenols on metabolic syndrome features in humans: a systematic review. Obes Rev. https://doi.org/10.1111/obr.12409

24. Marx W, Kelly J, Marshall S, Nakos S, Campbell K, Itsiopoulos C (2017) The effect of polyphenol-rich interventions on cardiovascular risk factors in haemodialysis: A systematic review and meta-analysis. Nutrients. https://doi.org/10.3390/nu9121345

25. Wiswedel I, Hirsch D, Kropf S et al (2004) Flavanol-rich cocoa drink lowers plasma F2-isoprostane concentrations in humans. Free Radic Biol Med. https://doi.org/10.1016/j.freeradbio med.2004.05.013

26. Forman HJ, Davies KJA, Ursini F (2014) How do nutritional antioxidants really work: nucleophilic tone and para-hormesis versus free radical scavenging in vivo. Free Radic Biol Med. https://doi.org/10.1016/j.freeradbiomed.2013.05.045

27. Martínez-Huélamo M, Rodríguez-Morató J, Boronat A, de la Torre R (2017) Modulation of Nrf2 by olive oil and wine polyphenols and neuroprotection. Antioxidants. https://doi. org/10.3390/antiox6040073

28. Scalbert A, Williamson G (2000) Dietary intake and bioavailability of polyphenols. J Nutr. https://doi.org/10.1093/jn/130.8.2073s

29. Bowtell J, Kelly V (2019) Fruit-derived polyphenol supplementation for athlete recovery and performance. Sport Med. https://doi. org/10.1007/s40279-018-0998-x

30. Cuadrado A, Rojo AI, Wells G et al (2019) Therapeutic targeting of the NRF2 and KEAP1 partnership in chronic diseases. Nat Rev Drug Discov. https://doi.org/10.1038/s41573-018-0008-X 
31. Itoh K, Wakabayashi N, Katoh Y et al (1999) Keap1 represses nuclear activation of antioxidant responsive elements by Nrf2 through binding to the amino-terminal Neh2 domain. Genes Dev. https://doi.org/10.1101/gad.13.1.76

32. Taguchi K, Fujikawa N, Komatsu M et al (2012) Keap1 degradation by autophagy for the maintenance of redox homeostasis. Proc Natl Acad Sci USA. https://doi.org/10.1073/pnas.11215 72109

33. Dinkova-Kostova AT, Wang XJ (2011) Induction of the Keap1/ Nrf2/ARE pathway by oxidizable diphenols. Chem-Biol Interactions. https://doi.org/10.1016/j.cbi.2010.09.010

34. Forman H, Maiorino M, Ursini F (2013) The false dichotomy of antioxidant defense and redox signaling. Free Radic Biol Med 65(SUPPL. 1):S8. https://doi.org/10.1016/j.freeradbio med.2013.08.121

35. Niture SK, Khatri R, Jaiswal AK (2014) Regulation of Nrf2-an update. Free Radic Biol Med 66:36-44. https://doi.org/10.1016/j. freeradbiomed.2013.02.008

36. Surh Y-J, Kundu JK, Na H-K (2008) Nrf2 as a master redox switch in turning on the cellular signaling involved in the induction of cytoprotective genes by some chemopreventive phytochemicals. Planta Med 74(13):1526-1539. https://doi. org/10.1055/s-0028-1088302

37. Li M, Huang W, Jie F et al (2019) Discovery of Keap1-Nrf2 small-molecule inhibitors from phytochemicals based on molecular docking. Food Chem Toxicol 133:110758. https:// doi.org/10.1016/j.fct.2019.110758

38. Christensen LP, Christensen KB (2013) The role of direct and indirect polyphenolic antioxidants in protection against oxidative stress. In: Christensen LP, Christensen KB (eds) Polyphenols in human health and disease. Elsevier, New York. https://doi. org/10.1016/B978-0-12-398456-2.00023-2

39. Ursini F, Maiorino M, Forman H (2016) Redox homeostasis: The Golden Mean of healthy living. Redox Biol 8:205-215. https:// doi.org/10.1016/j.redox.2016.01.010

40. Itoh K, Chiba T, Takahashi S et al (1997) An Nrf2/small Maf heterodimer mediates the induction of phase II detoxifying enzyme genes through antioxidant response elements. Biochem Biophys Res Commun. https://doi.org/10.1006/bbrc.1997.6943

41. Jaiswal AK (2004) Nrf2 signaling in coordinated activation of antioxidant gene expression. Free Radic Biol Med. https://doi. org/10.1016/j.freeradbiomed.2004.02.074

42. Surh YJ, Kundu JK, Na HK (2008) Nrf2 as a master redox switch in turning on the cellular signaling involved in the induction of cytoprotective genes by some chemopreventive phytochemicals. Planta Med. https://doi.org/10.1055/s-0028-1088302

43. Cuadrado A, Manda G, Hassan A et al (2018) Transcription factor NRF2 as a therapeutic target for chronic diseases: a systems medicine approach. Pharmacol Rev 70(2):348-383. https://doi. org/10.1124/pr.117.014753

44. Zhang H, Tsao R (2016) Dietary polyphenols, oxidative stress and antioxidant and anti-inflammatory effects. Curr Opin Food Sci. https://doi.org/10.1016/j.cofs.2016.02.002

45. Ghanim H, Sia CL, Korzeniewski K et al (2011) A resveratrol and polyphenol preparation suppresses oxidative and inflammatory stress response to a high-fat, high-carbohydrate meal. J Clin Endocrinol Metab 96(5):1409-1414. https://doi.org/10.1210/ jc.2010-1812

46. Wise RA, Holbrook JT, Criner G et al (2016) Lack of effect of oral sulforaphane administration on Nrf2 expression in COPD: a randomized, double-blind, placebo controlled trial. PLoS ONE 11(11):e0163716. https://doi.org/10.1371/journal.pone.0163716

47. Bardagjy AS, Hu Q, Giebler KA, Ford A, Steinberg FM (2018) Effects of grape consumption on biomarkers of inflammation, endothelial function, and PBMC gene expression in obese subjects. Arch Biochem Biophys. https://doi.org/10.1016/j. abb.2018.04.003

48. Moher D, Liberati A, Tetzlaff J et al (2009) Preferred reporting items for systematic reviews and meta-analyses: the PRISMA statement. PLoS Med. https://doi.org/10.1371/journ al.pmed.1000097

49. Guan VX, Mobasheri A, Probst YC (2019) A systematic review of osteoarthritis prevention and management with dietary phytochemicals from foods. Maturitas. https://doi.org/10.1016/j.matur itas.2019.01.005

50. Carnauba RA, Chaves DFS, Baptistella AB, Paschoal V, Naves A, Buehler AM (2017) Association between high consumption of phytochemical-rich foods and anthropometric measures: a systematic review. Int J Food Sci Nutr. https://doi. org/10.1080/09637486.2016.1229761

51. Volz N, Boettler U, Winkler S et al (2012) Effect of coffee combining green coffee bean constituents with typical roasting products on the Nrf2/ARE pathway in vitro and in vivo. J Agric Food Chem. https://doi.org/10.1021/jf302258u

52. Jackman SR, Brook MS, Pulsford RM et al (2018) Tart cherry concentrate does not enhance muscle protein synthesis response to exercise and protein in healthy older men. Exp Gerontol. https ://doi.org/10.1016/j.exger.2018.06.007

53. Higgins JPT, Altman DG, Gøtzsche PC et al (2011) The Cochrane Collaboration's tool for assessing risk of bias in randomised trials. BMJ. https://doi.org/10.1136/bmj.d5928

54. Yang H, Xu W, Zhou Z et al (2015) Curcumin attenuates urinary excretion of albumin in type II diabetic patients with enhancing nuclear factor erythroid-derived 2-like 2 (Nrf2) system and repressing inflammatory signaling efficacies. Exp Clin Endocrinol Diabetes 123(6):360-367. https://doi. org/10.1055/s-0035-1545345

55. Cheng D, Li W, Wang L et al (2019) Pharmacokinetics, pharmacodynamics, and PKPD modeling of curcumin in regulating antioxidant and epigenetic gene expression in healthy human volunteers. Mol Pharm 16(5):1881-1889. https://doi.org/10.1021/ acs.molpharmaceut.8b01246

56. Jimenez-Osorio AS, Garcia-Nino WR, Gonzalez-Reyes S et al (2016) The effect of dietary supplementation with curcumin on redox status and Nrf2 activation in patients with nondiabetic or diabetic proteinuric chronic kidney disease: a pilot study. J Ren Nutr 26(4):237-244. https://doi.org/10.1053/j.jrn.2016.01.013

57. Seyyedebrahimi S, Khodabandehloo H, Nasli Esfahani E, Meshkani R (2018) The effects of resveratrol on markers of oxidative stress in patients with type 2 diabetes: a randomized, doubleblind, placebo-controlled clinical trial. Acta Diabetol 55(4):341353. https://doi.org/10.1007/s00592-017-1098-3

58. Saldanha JF, Leal VO, Rizzetto F et al (2016) Effects of resveratrol supplementation in Nrf2 and NF-kappaB expressions in nondialyzed chronic kidney disease patients: a randomized, double-blind, placebo-controlled. Crossover Clinical Trial J Ren Nutr 26(6):401-406. https://doi.org/10.1053/j.jrn.2016.06.005

59. Kerns ML, Guss L, Fahey J et al (2017) Randomized, split-body, single-blinded clinical trial of topical broccoli sprout extract: assessing the feasibility of its use in keratin-based disorders. J Am Acad Dermatol 76(3):449-453.e1. https://doi.org/10.1016/j. jaad.2016.10.009

60. Duran CG, Burbank AJ, Mills KH et al (2016) A proof-of-concept clinical study examining the NRF2 activator sulforaphane against neutrophilic airway inflammation. Respir Res 17(1):89. https://doi.org/10.1186/s12931-016-0406-8

61. Boettler U, Sommerfeld K, Volz N et al (2011) Coffee constituents as modulators of Nrf2 nuclear translocation and ARE (EpRE)-dependent gene expression. J Nutr Biochem 22(5):426440. https://doi.org/10.1016/j.jnutbio.2010.03.011 
62. Li Y, Zhang H (2017) Soybean isoflavones ameliorate ischemic cardiomyopathy by activating Nrf2-mediated antioxidant responses. Food Funct 8(8):2935-2944. https://doi.org/10.1039/ c7fo00342k

63. Magbanua MJM, Roy R, Sosa EV et al (2011) Gene expression and biological pathways in tissue of men with prostate cancer in a randomized clinical trial of lycopene and fish oil supplementation. PLoS ONE 6(9):e24004. https://doi.org/10.1371/journ al.pone.0024004

64. Yubero-Serrano EM, Gonzalez-Guardia L, Rangel-Zuniga O et al (2013) Postprandial antioxidant gene expression is modified by Mediterranean diet supplemented with coenzyme Q(10) in elderly men and women. Age (Dordr) 35(1):159-170. https:// doi.org/10.1007/s11357-011-9331-4

65. Perez-Herrera A, Rangel-Zuniga OA, Delgado-Lista J et al (2013) The antioxidants in oils heated at frying temperature, whether natural or added, could protect against postprandial oxidative stress in obese people. Food Chem 138(4):2250-2259. https://doi.org/10.1016/j.foodchem.2012.12.023

66. Kropat C, Mueller D, Boettler U et al (2013) Modulation of Nrf2dependent gene transcription by bilberry anthocyanins in vivo. Mol Nutr Food Res 57(3):545-550. https://doi.org/10.1002/ mnfr.201200504

67. Bardagjy AS, Hu Q, Giebler KA, Ford A, Steinberg FM (2018) Effects of grape consumption on biomarkers of inflammation, endothelial function, and PBMC gene expression in obese subjects. Arch Biochem Biophys 646:145-152. https://doi. org/10.1016/j.abb.2018.04.003

68. Castejon ML, Sánchez-Hidalgo M, Aparicio-Soto M, GonzálezBenjumea A, Fernández-Bolaños JG, Alarcón-de-la-Lastra C (2019) Olive secoiridoid oleuropein and its semisynthetic acetyl-derivatives reduce LPS-induced inflammatory response in murine peritoneal macrophages via JAK-STAT and MAPKs signaling pathways. J Funct Foods. 58:95-104. http://search.ebsco host.com/login. aspx $?$ direct $=$ true $\& d b=l a h \& A N=2019334942$ $2 \&$ site $=$ ehost-live.

69. Kim KH, Lyu JH, Jung J, Sadikot RT, Blackwell T, Freeman M, Christman JW, Joo M. NRF2 physically interacted with p47phox, a subunit of nadph oxidase, increasing the expression of genes governed by NRF2. Am J Respir Crit Care Med. 2012;185(MeetingAbstracts). http://www.atsjournals.org/doi/pdf/https://doi. org/10.1164/ajrccm-conference.2012.185.1_MeetingAbstract s.A1362.

70. Ferguson JF, Allayee H, Gerszten RE et al (2016) Nutrigenomics, the microbiome, and gene-environment interactions: New directions in cardiovascular disease research, prevention, and treatment. Circ Cardiovasc Genet. https://doi.org/10.1161/ HCG.0000000000000030

71. Schulz KF, Altman DC, Moher DCONSORT (2010) Statement: updated guidelines for reporting parallel group randomised trials. Ital J Public Health. https://doi.org/10.4178/epih/e2014029

72. Zhao R, Yang B, Wang L et al (2013) Curcumin protects human keratinocytes against inorganic arsenite-induced acute cytotoxicity through an NRF2-dependent mechanism. Oxid Med Cell Longev. https://doi.org/10.1155/2013/412576

73. Balogun E, Hoque M, Gong P, Killeen E, Green CJ, Foresti R, Alam J, Motterlini R (2003) Curcumin activates the haem oxygenase- 1 gene via regulation of $\mathrm{Nrf} 2$ and the antioxidant-responsive element. Biochem J 371(3):887-895. https://doi.org/10.1042/ BJ20021619

74. Ungvari Z, Csiszar A (2011) Resveratrol confers endothelial protection in insulin-dependent diabetes mellitus: editorial to: "Resveratrol shows vasoprotective effect reducing oxidative stress without affecting metabolic disturbances in insulindependent diabetes of rabbits" by F. Akar Cardiovasc Drugs Ther 25(2):111-113. https://doi.org/10.1007/s10557-010-6267-3
75. Gurusinghe S, Cox AG, Rahman R et al (2017) Resveratrol mitigates trophoblast and endothelial dysfunction partly via activation of nuclear factor erythroid 2-related factor-2. Placenta 60:74-85. https://doi.org/10.1016/j.placenta.2017.10.008

76. Hao E, Lang F, Chen Y et al (2013) Resveratrol alleviates endotoxin-induced myocardial toxicity via the Nrf2 transcription factor. PLoS ONE. https://doi.org/10.1371/journ al.pone. 0069452

77. Jurrmann N, Brigelius-Flohé R, Böl GF (2005) Curcumin blocks interleukin-1 (IL-1) signaling by inhibiting the recruitment of the IL-1 receptor-associated kinase IRAK in murine thymoma EL-4 cells. J Nutr. https://doi.org/10.1093/ jn/135.8.1859

78. Bhaumik S, Jyothi MD, Khar A (2000) Differential modulation of nitric oxide production by curcumin in host macrophages and NK cells. FEBS Lett. https://doi.org/10.1016/S0014-5793(00)02089 $-5$

79. Jung KK, Lee HS, Cho JY et al (2006) Inhibitory effect of curcumin on nitric oxide production from lipopolysaccharideactivated primary microglia. Life Sci. https://doi.org/10.1016/j. lfs. 2006.06 .048

80. Jackson MJ (1999) An overview of methods for assessment of free radical activity in biology. Proc Nutr Soc. https://doi. org/10.1017/S0029665199001317

81. Margaritelis NV, Cobley JN, Paschalis V et al (2016) Going retro: Oxidative stress biomarkers in modern redox biology. Free Radic Biol Med. https://doi.org/10.1016/j.freeradbiomed.2016.02.005

82. Houghton CA (2019) Sulforaphane: its "Coming of Age" as a clinically relevant nutraceutical in the prevention and treatment of chronic disease. Oxid Med Cell Longev 2019:2716870. https ://doi.org/10.1155/2019/2716870

83. Hu C, Eggler AL, Mesecar AD, Van Breemen RB (2011) Modification of Keap1 cysteine residues by sulforaphane. Chem Res Toxicol. https://doi.org/10.1021/tx100389r

84. Kensler TW, Egner PA, Agyeman AS et al (2012) Keap1-Nrf2 signaling: a target for cancer prevention by sulforaphane. In: Pezzuto JM, Suh N (eds) Natural products in cancer prevention and therapy. Springer, Berlin. https://doi.org/10.1007/128_2012_339

85. Houghton CA, Fassett RG, Coombes JS (2013) Sulforaphane: translational research from laboratory bench to clinic. Nutr Rev 71(11):709-726. https://doi.org/10.1111/nure.12060

86. Riedl MA, Saxon A, Diaz-Sanchez D (2009) Oral sulforaphane increases Phase II antioxidant enzymes in the human upper airway. Clin Immunol. https://doi.org/10.1016/j.clim.2008.10.007

87. López-Chillón MT, Carazo-Díaz C, Prieto-Merino D, Zafrilla P, Moreno DA, Villaño D (2019) Effects of long-term consumption of broccoli sprouts on inflammatory markers in overweight subjects. Clin Nutr. https://doi.org/10.1016/j.clnu.2018.03.006

88. Mirmiran P, Bahadoran Z, Hosseinpanah F, Keyzad A, Azizi F (2012) Effects of broccoli sprout with high sulforaphane concentration on inflammatory markers in type 2 diabetic patients: a randomized double-blind placebo-controlled clinical trial. J Funct Foods. https://doi.org/10.1016/j.jff.2012.05.012

89. Kivelä AM, Mäkinen PI, Jyrkkänen HK et al (2010) Sulforaphane inhibits endothelial lipase expression through NF- $\mathrm{KB}$ in endothelial cells. Atherosclerosis. https://doi.org/10.1016/j.atheroscle rosis.2010.07.015

90. Zhang H, Davies KJA, Forman HJ (2015) Oxidative stress response and Nrf2 signaling in aging. Free Radic Biol Med. https ://doi.org/10.1016/j.freeradbiomed.2015.05.036

91. Ren HL, Lv CN, Xing Y et al (2018) Downregulated nuclear factor E2-related factor 2 (Nrf2) aggravates cognitive impairments via neuroinflammation and synaptic plasticity in the senescenceaccelerated mouse prone 8 (SAMP8) mouse: a model of accelerated senescence. Med Sci Monit. https://doi.org/10.12659/ MSM.908954 
92. Rabbani PS, Soares MA, Hameedi SG et al (2019) Dysregulation of Nrf2/Keap1 redox pathway in diabetes affects multipotency of stromal cells. Diabetes. https://doi.org/10.2337/db18-0232

93. Tian C, Gao L, Zimmerman MC, Zucker IH (2018) Myocardial infarction-induced microRNA-enriched exosomes contribute to cardiac Nrf2 dysregulation in chronic heart failure. Am J Physiol Hear Circ Physiol. https://doi.org/10.1152/ajpheart.00602.2017

94. Zhu F, Du B, Xu B (2018) Anti-inflammatory effects of phytochemicals from fruits, vegetables, and food legumes: a review. Crit Rev Food Sci Nutr. https://doi.org/10.1080/10408 398.2016.1251390

95. Tang X, Wang H, Fan L et al (2011) Luteolin inhibits Nrf2 leading to negative regulation of the Nrf2/ARE pathway and sensitization of human lung carcinoma A549 cells to therapeutic drugs. Free Radic Biol Med 50(11):1599-1609. https://doi. org/10.1016/j.freeradbiomed.2011.03.008

96. Robledinos-Anton N, Fernandez-Gines R, Manda G, Cuadrado A (2019) Activators and inhibitors of NRF2: a review of their potential for clinical development. Oxid Med Cell Longev 2019:9372182. https://doi.org/10.1155/2019/9372182

97. Milkovic L, Zarkovic N, Saso L (2017) Controversy about pharmacological modulation of Nrf2 for cancer therapy. Redox Biol 12:727-732. https://doi.org/10.1016/j.redox.2017.04.013

98. Rudkowska I, Raymond C, Ponton A et al (2011) Validation of the use of peripheral blood mononuclear cells as surrogate model for skeletal muscle tissue in nutrigenomic studies. Omi A J Integr Biol. https://doi.org/10.1089/omi.2010.0073

99. Liew CC, Ma J, Tang HC, Zheng R, Dempsey AA (2006) The peripheral blood transcriptome dynamically reflects system wide biology: a potential diagnostic tool. J Lab Clin Med. https://doi. org/10.1016/j.lab.2005.10.005

100. Turowski JB, Pietrofesa RA, Lawson JA, Christofidou-Solomidou M, Hadjiliadis D (2015) Flaxseed modulates inflammatory and oxidative stress biomarkers in cystic fibrosis: a pilot study. BMC Complement Altern Med 15:148. https://doi.org/10.1186/s1290 6-015-0651-2

101. Appendino G, Belcaro G, Cornelli U, et al (2011) Potential role of curcumin phytosome (Meriva) in controlling the evolution of diabetic microangiopathy. A pilot study. Panminerva Med 53(3 Suppl 1):43-49. http://ovidsp.ovid.com/ovidweb.cgi?T=JS\&PAGE=refer ence $\& D=$ med $8 \& N E W S=N \& A N=22108476$.

102. Fürst R, Blumenthal SB, Kiemer AK, Zahler S, Vollmar AM (2006) Nuclear factor- $\mathrm{\kappa B}$-independent anti-inflammatory action of salicylate in human endothelial cells: Induction of heme oxygenase- 1 by the c-Jun $\mathrm{N}$-terminal kinase/activator protein-1 pathway. J Pharmacol Exp Ther. https://doi.org/10.1124/ jpet.106.102251

103. Milani P, Gagliardi S, Cova E, Cereda C (2011) SOD1 transcriptional and posttranscriptional regulation and its potential implications in ALS. Neurol Res Int. https://doi.org/10.1155/2011/45842 7

104. Glorieux C, Zamocky M, Sandoval JM, Verrax J, Calderon PB (2015) Regulation of catalase expression in healthy and cancerous cells. Free Radic Biol Med. https://doi.org/10.1016/j.freer adbiomed.2015.06.017

105. Muramatsu H, Katsuoka F, Toide K, Shimizu Y, Furusako S, Yamamoto M (2013) Nrf2 deficiency leads to behavioral, neurochemical and transcriptional changes in mice. Genes Cells. https ://doi.org/10.1111/gtc.12083

106. Jangra A, Kwatra M, Singh T et al (2016) Piperine augments the protective effect of curcumin against lipopolysaccharide-induced neurobehavioral and neurochemical deficits in mice. Inflammation. https://doi.org/10.1007/s10753-016-0332-4

107. Antony B, Merina B, Iyer V, Judy N, Lennertz K, Joyal S (2008) A pilot cross-over study to evaluate human oral bioavailability of BCM-95® $\mathrm{CG}$ (Biocurcumax ${ }^{\mathrm{TM}}$ ), a novel bioenhanced preparation of curcumin. Indian J Pharm Sci. https://doi. org/10.4103/0250-474X.44591

Publisher's Note Springer Nature remains neutral with regard to jurisdictional claims in published maps and institutional affiliations. 